\title{
EDITORIAL
}

\section{Bedside Teaching in Clinical Medicine}

Bedside teaching is a specialized form of small group teaching that takes place in the presence of the patient. Although it is known to enhance a student's learning experience and improve patient care, the use of this type of teaching is unfortunately in steady decline ${ }^{1}$. As well as in the hospital setting, bedside teaching skills can be used elsewhere, such as long term care facilities and in the office ${ }^{2}$. Bedside teaching is still valued by patients, as well as students, residents and clinical teachers as a very useful teaching method. Because of its value for students/residents, patients and medical teachers, obstacles to bedside teaching should be overcome. Solutions vary from practical guidelines to using residents and interns as bedside teachers ${ }^{3}$.

Bedside teaching is declining in the medical curriculum. Traditionally, bedside teaching has always been seen as a primary teaching modality in which most aspects of clinical practice can be demonstrated and trained. It was widely used across medical schools in the first half of the previous century, and was estimated to represent as much as $75 \%$ of all clinical training in the $1960 \mathrm{~s}^{4}$. The recent explosion of imaging and laboratory testing has decreased its use ${ }^{5}$. Today's estimates range from 8 $19 \%$, if at all present in medical training ${ }^{3,6}$. Bedside teaching has been described as one of the ideal clinical teaching modalities, in which history taking and physical examination skills, together with professional attitude, can be combined to provide a holistic approach in the diagnostic process and in patient care. Students and residents are found to be motivated to engage in clinical reasoning and problem-solving if their preceptor, acting as a role model, provides adequate demonstration and guidance $^{3,6-9}$.

Bedside teaching can improve students' history taking, examination skills, and knowledge of clinical ethics, can teach them professionalism, and can foster good communication and role modelling skills ${ }^{11-15}$. The educational sessions integrate theory, practical skills, and patient contact to make the educational process as realistic as possible, and they allow the students to develop empathy with the patients ${ }^{15}$. Teaching small groups in the presence of the patient allows trainees to be closely observed and taught clinical practice and medical examinations. Rather than listening to a presentation or reading from a blackboard, learners have the opportunity to use most of their senses - hearing, vision, smell, and touch - to learn more about the patient and his or her problems ${ }^{2}$.

In clinical medicine, $56 \%$ of patients' problems can be diagnosed after taking a comprehensive history, and this rises to $73 \%$ by the end of a physical examination ${ }^{15-16}$. For certain problems, this percentage can be over $90 \%{ }^{10}$. Along with this decrease, a decline in overall clinical skills among trainees and junior faculty members has been observed ${ }^{17}$. Various obstacles that prevent doctors from teaching at the bedside have been cited, and a considerable number of studies have stated "lack of time" as the single most important factor. Possible reasons for this are the increased pressure to see more patients, more demand for paperwork, rapid patient discharge, and over-reliance on technology. The other reasons for the decline in bedside teaching is the changing nature of teaching hospitals, especially the shortened admittance of patients, which increases the workload of physicians while decreasing the potential suitability of patients for bedside rounds ${ }^{8}$. The practical hindrances for teaching mentioned vary from time constraints, patients not being in bed and noise on the ward, but also poor clinical skills and knowledge of students ${ }^{9}$.

Observing the trainee's interaction with the patient can help teachers to evaluate trainees' clinical skills, bedside manner, professionalism, attitude, and knowledge ${ }^{18}$. Every learner should be given the opportunity to participate and the teacher should try not to ask excessively difficult questions that may demoralise a student. At the end of the teaching session there should be a feedback session to summarise what has been taught, and adequate time should be available for discussion ${ }^{19}$. The teacher should reflect on the teaching encounter in order to improve and better prepare for the next encounter. 
In all aspects of bed side teaching minimum to considerable efforts are necessary to make it more effective. A bedside teacher must know the importance of comfortable physical environment in learning and must learn how to involve patients and learners in the educational process, so faculty development is essential. It would be appropriate to conclude with William Osler's words: "To study the phenomenon of disease without books is to sail an uncharted sea, while to study books without patients is not to go to sea at all" (Osler, 1903).

(J Bangladesh Coll Phys Surg 2017; 35: 161-162)

\section{Professor Dr. Md. Ridwanur Rahman}

Head, Universal Medical College Research Center, Mohakhali, Dhaka 1215.

\section{References:}

1. La Combe MA. On bedside teaching. Ann Int Med 1997;126:217-20.

2. MAHEC Office of Regional Primary Care Education. Teaching at the bedside, 2009.

3. Max Peters \& Olle Ten Cate. Bedside teaching in medical education. Perspect Med Educ 2014 Apr; 3(2): 76-88.

4. Fitzgerald FT. Bedside teaching. West J Med 1993;158: 418-20.

5. Ramani S. Twelve tips to improve bedside teaching. Med Teacher 2003;25:112-5.

6. Jenkins C, Page C, Hewamana S, Brigley S. Techniques for effective bedside teaching. Brit J Hosp Med 2007;68:M150-3.
7. Ahmed M El-Bagir. What is happening to bedside teaching? Med Educ 2002;36:1185-8.

8. Saunder G. The importance of history in the medical clinic and the cost of unnecessary tests. Am Heart $J$ 1980;100: 928-31.

9. Tremonti LP, Biddle WP. Teaching behaviours of residents and faculty members. $J$ Med Educ 1982;26:669-72.

10. Mangione S, Nieman LZ, Gracely E, Kaye D. The teaching and practice of cardiac auscultation during internal medicine and cardiology training: a nationwide survey. Ann Int Med 1993;119:47-54.

11. Wang-Cheng RM, Barnas GP, Sigmann P, Riendl PA, Young MJ. Bedside case presentations: why patients like them but learners don't. J Gen Int Med 1989;4:284-7.

12. Kronke K. Attending rounds revisited (president's column). Soc Gen Int Med Forum 2001;24:8-9.

13. Stone MJ. The wisdom of Sir William Osler. Am J Cardiol. 1995;75:269-276. doi: 10.1016/0002-9149(95).

14. Lindeboom GA, Boerhaave H. Teacher of all Europe. JAMA. 1968;206:2297-2301.

15. Crumlish CM, Yialamas MA, McMahon GT. Quantification of bedside teaching by an academic hospitalist group. J Hosp Med. 2009;4:304-307.

16. Verghese A, Brady E, Kapur CC, Horwitz RI. The bedside evaluation: ritual and reason. Ann Intern Med. 2011;155: $550-553$.

17. LaCombe MA. On bedside teaching. Ann Intern Med. $1997 ; 126: 217-220$

18. Kroenke K, Omori DM, Landry FJ, Lucey CR. Bedside teaching. South Med J. 1997;90:1069-1074. 